Supporting Information

\title{
Carrier-Free Triterpene Prodrugs with Glutathione Response and Biosafety for Synergistically Enhanced Photochemotherapy
}

Jianjun Cheng ${ }^{\dagger}$, Xinyu $\mathrm{Li}^{\dagger}$, Shu Wang ${ }^{\dagger}$ Ying Han ${ }^{\dagger}$, Haitian Zhao ${ }^{\dagger}$, Xin Yang ${ }^{* \dagger}$.

${ }^{\dagger}$ School of Chemistry and Chemical Engineering, Harbin Institute of Technology,

No. 92 West Dazhi Street, Nan Gang District, Harbin, 150001, China.

*Corresponding author. Tel.: +86 451 86403309; Fax: +86 45186403379.

E-mail: yangxin@hit.edu.cn (Xin Yang) 


\section{Materials and Instruments}

All organic solvents were purchased from Sinopharm Chemical Reagent Co., Ltd (Shanghai, China). Betulinic acid (BA), Stigmasterol (ST), 3, 3'-dithiodipropionic acid, dicyclohexylcarbodiimide (DCC), 4-dimethylaminopyridine (DMAP) were purchased from Aladdin Reagent Company. Ce6 was purchased from Jinan Daen Pharmaceutical Technology Co., Ltd (Shang Dong, China). Fetal bovine serum (FBS), penicillin-streptomycin, phosphate buffered saline (PBS), trypsin and RPMI 1640 Medium were purchased from purchased from Sigma Gibco (Grand Island, NY, USA). Methylene blue (MB), 4,6-diamino-2-phenyl-indole (DAPI), Dichlorofluorescin diacetate (DCFH-DA) were purchased from Alfa Aesar Chemical Company. 1, 3-diphenylisobenzofuran (DPBF) and 3-(4,5dimethylthiazol-2-yl)-2,5-dipheny-ltetrazolium bromide (MTT) were purchased from Sigma-Aldrich Chemical Company. All chemical reagents were used without further purification.

The 1D NMR experiments were performed on a Bruker DRX-400 (Rheinstetten, Germany) at 400 MHz. UV-Vis spectra was obtained on a TU-1900 PERSEE spectrometer (Beijing, China). Fourier transform infrared (FT-IR) spectra were acquired using $\mathrm{KBr}$ disc samples in Nicolet iS5 (Thermo fisher, USA). Elemental analysis was measured with a Vario Microcube analyzer (Elementar, Germany). Scanning electron transmission (SEM) images were recorded on aluminum foil plate using a Quanta 200FEG electron microscope operating at $20 \mathrm{kV}$. Transmission electron microscope (TEM) images was recorded on a Tecnai G2 F20S-TWIN (FEI, America) operating at $200 \mathrm{kV}$. The size distributions and Zeta potential were carried out with Zetasizer Nano ZS 90 (Malvern, UK). And irradiation was performed using Solar-500 with a Xenon lamp (NBET, Beijing, China) with central wavelengths at $675 \pm 10 \mathrm{~nm}$. The cells were imaged using a fluorescence inverted microscope (UOP, DSY-2000X). A AllSHENG AMR-100 absorbance microplate reader was used in the MTT assay.

\section{Synthesis of 3-(3, 3'-dithiodipropionic acid) betulinic acid (BA-S-S)}

Betulinic acid (115 mg, $0.26 \mathrm{mmol})$ and 3,3'-dithiodipropionic acid (110 $\mathrm{mg}, 0.52 \mathrm{mmol})$ were dissolved in dried $\mathrm{CH}_{2} \mathrm{Cl}_{2}(7 \mathrm{~mL})$ and DMF $(1 \mathrm{~mL})$. After stirring in ice water bath for $15 \mathrm{~min}$, DCC (66 mg, $0.32 \mathrm{mmol}$ ) and DMAP (39 $\mathrm{mg}, 0.32 \mathrm{mmol}$ ) were added into the mixture, and subsequently stirred for $24 \mathrm{~h}$ under ice water. Then, the reaction mixture was evaporated and purified on a silica gel column using petroleum ether: ethyl acetate (10:3, v/v) as eluent to afford white 3-(3, 3'dithiodipropionic acid) betulinic acid (BA-S-S, yield: 84\%). ${ }^{1} \mathrm{H}-\mathrm{NMR}$ (400 MHz, DMSO-D6) $\delta: 6.09$ $(1 \mathrm{H}, \mathrm{s},-\mathrm{COOH}) 6.00(1 \mathrm{H}, \mathrm{s},-\mathrm{COOH}), 4.40(1 \mathrm{H}, \mathrm{dd}, \mathrm{J}=3.2,8 \mathrm{~Hz}, \mathrm{H}-3), 4.56(1 \mathrm{H}$, br s, H-29 $), 4.68$ (1H, br s, H-29ß), 2.97-3.02 (4H, m, H-33 and H-34), 2.91 (2H, t, H-32, J=4.4 Hz), 2.86 (2H, t, H-35, $\mathrm{J}=2.4 \mathrm{~Hz}), 0.79\left(3 \mathrm{H}, \mathrm{s}, \mathrm{CH}_{3}-24\right), 0.80\left(3 \mathrm{H}, \mathrm{s}, \mathrm{CH}_{3}-25\right), 0.87\left(3 \mathrm{H}, \mathrm{s}, \mathrm{CH}_{3}-23\right) 0.94\left(3 \mathrm{H}, \mathrm{s}, \mathrm{CH}_{3}-26\right), 0.97$

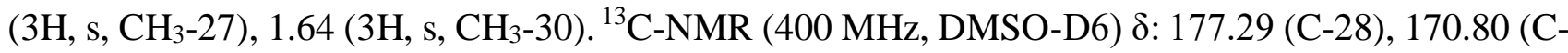
36), 158.29 (C-31), 150.35 (C-20), 109.71(C-29), 80.42 (C-3), 55.44, 55.17, 54.97, 54.63, 49.65, 48.54, 
$46.64,42.96,42.06,40.27,37.45,36.69,36.65,34.10,33.73,33.38,32.98,29.23,27.73,26.11,25.37$, 24.49, 23.39, 20.48, 18.96, 17.75, 16.48, 15.89, 15.72, 14.39. Anal. Calcd for $\mathrm{C}_{36} \mathrm{H}_{56} \mathrm{O}_{6} \mathrm{~S}_{2}: \mathrm{C} 66.63, \mathrm{H}$ 8.70, S 9.88; found C 66.42, H 9.05, S 10.12.

\section{Synthesis of 3-(3, 3'-dithiodipropionic acid) stigmasterol (ST-S-S)}

Stigmasterol (100 mg, $0.24 \mathrm{mmol}$ ) and 3,3'-dithiodipropionic acid (102 $\mathrm{mg}, 0.52 \mathrm{mmol}$ ) were dissolved in dried $\mathrm{CH}_{2} \mathrm{Cl}_{2}(6 \mathrm{~mL})$ and DMF $(1 \mathrm{~mL})$. Then the mixture were stirred at ice water bath for $15 \mathrm{~min}$. Subsequently, DCC (75 mg, $0.36 \mathrm{mmol}$ ) and DMAP (44 mg, $0.36 \mathrm{mmol}$ ) were added into the mixture, and stirred for $24 \mathrm{~h}$ under ice water. Finally, the mixture was evaporated and purified on a silica gel column using petroleum ether: ethyl acetate $(5: 1, \mathrm{v} / \mathrm{v})$ as eluent to afford white $3-\left(3,3{ }^{\prime}-\right.$ dithiodipropionic acid) stigmasterol (ST-S-S, yield: 87\%). ${ }^{1} \mathrm{H}-\mathrm{NMR}\left(400 \mathrm{MHz}, \mathrm{CDCl}_{3}\right) \delta: 5.37(1 \mathrm{H}, \mathrm{s}$, H-6), 5.13-5.17 (1H, dd, J=6.8 Hz, 12Hz, H-23), 4.99-5.04 (1H, dd, J=6.8 Hz, 12Hz, H-22), 4.63 (1H, m, H-3); 2.91-2.94 (4H, t, H-31 and H-34); 2.80 (2H, t, H-32); 2.71 (2H, t, H-35); 0.70-2.33 (43H, m, for stigmasteryl protons). ${ }^{13} \mathrm{C}-\mathrm{NMR}\left(400 \mathrm{MHz}, \mathrm{CDCl}_{3}\right) \delta 177.09$ (C-35), 171.23 (C-30), 139.67 (C-5), 138.44 (C-22), 129.46 (C-23), 122.91 (C-6), 74.71 (C-3), 56.94, 56.11, 51.38, 50.21, 42.37, 40.62, 39.78, 38.24, 37.12, 36.76, 34.62, 34.01, 33.54, 33.00, 32.03, 29.04, 27.92, 25.61, 25.54, 24.87, 24.51, 21.37, 21.22, 21.18, 19.46, 19.14, 12.38, 12.20. Anal. Calcd for $\mathrm{C}_{35} \mathrm{H}_{56} \mathrm{O}_{4} \mathrm{~S}_{2}$ : C 69.49, H 9.33 S 10.60; found: C 69.75, H 9.03 S 10.48.

\section{Preparation of co-assembled BA-S-S/Ce6 NPs and ST-S-S/Ce6 NPs}

The co-assembled BA-S-S/Ce6 NPs were prepared by one step reprecipitation method. Briefly, BAS-S (33.6 mM) and Ce6 (33.6 mM) DMSO stock solutions were first prepared. Then, $5 \mu \mathrm{L}$ of Ce6 and $20 \mu \mathrm{L}$ of BA-S-S solution were mixed with the molar ratio of $1: 4$, and subsequently injected rapidly into $1 \mathrm{~mL}$ of water containing $10 \mu \mathrm{L} \mathrm{NaOH}(51 \mathrm{mM})$ under ultrasonication. After further ultrasonication for $10 \mathrm{~min}$, the BA-S-S/Ce6 NPs were obtained. Other formulations with different molar ratios of $\mathrm{Ce} 6$ to $\mathrm{BA}-\mathrm{S}-\mathrm{S}$ were also prepared by the same procedure with a constant $\mathrm{NaOH}$ to Ce6 molar ratio of 3:1. For the preparation of another ST-S-S mediated ST-S-S/Ce6 co-assemblies, a molar ratio of Ce6 to ST-S-S (1:4) was chosen by exploring the same method as described above.

\section{In vitro Ce6 release studies}

The in vitro release profiles were investigated by a dialysis method. First, $1 \mathrm{~mL}$ of BA-S-S/Ce6 NPs (equivalent Ce6: $80 \mu \mathrm{g} / \mathrm{mL}$ ) PBS ( $\mathrm{pH} 7.4$ or 6.5 ) solutions were transferred to dialysis bags $(\mathrm{MWCO}=14000 \mathrm{Da})$, and subsequently incubated in $100 \mathrm{~mL}$ of release medium containing $0.05 \%$ Tween 80 at a speed of $100 \mathrm{r} / \mathrm{min}$. At predetermined time points, $30 \mu \mathrm{L}$ of sample solutions were taken out from dialysis bags and dissolved in DMSO for determination of residual Ce6 by Uv-vis absorption spectroscopy. Meanwhile, $2 \mathrm{~mL}$ of medium outside of the dialysis tube was displaced with fresh buffer 
solution. For the investigation of the reduction sensitive properties of drug delivery systems, an additional $4 \mathrm{mM}$ of glutathione (GSH) was added to PBS (pH 7.4) solution as a GSH-sensitive group.

\section{Measurement of ${ }^{1} \mathrm{O}_{2}$ quantum yield}

The ${ }^{1} \mathrm{O}_{2}$ quantum yield of BA-S-S/Ce6 NPs was evaluated by employing the decomposition reaction of 1,3-diphenylisobenzofuran (DPBF). Briefly, $20 \mu \mathrm{L}$ of BA-S-S/Ce6 NPs or free Ce6 (equivalent Ce6: $\left.2.8 \times 10^{-5} \mathrm{~mol} / \mathrm{L}\right)$ water solutions were added into $3 \mathrm{~mL}$ of $\mathrm{DPBF}\left(6 \times 10^{-5} \mathrm{~mol} / \mathrm{L}\right)$. Then the mixture was irradiated with light $(675 \pm 10 \mathrm{~nm})$ for a $60 \mathrm{~s}$ period and measured at $418 \mathrm{~nm}$ with a UV-Vis spectrophotometer. Methylene blue (MB) $(\Phi=0.52)$ in DMSO was used as the reference compound. And the ${ }^{1} \mathrm{O}_{2}$ quantum yield $(\Phi)$ was calculated using the following equation:

$$
\Phi^{\mathrm{s}}=\Phi(\mathrm{MB}) \times \frac{\mathrm{m}^{\mathrm{s}} \times \mathrm{F}(\mathrm{MB}) \times \mathrm{P}(\mathrm{MB})}{\mathrm{m}(\mathrm{MB}) \times \mathrm{F}^{\mathrm{s}} \times \mathrm{P}^{\mathrm{s}}}
$$

In the formula, $\Phi$ was the quantum yield of ${ }^{1} \mathrm{O}_{2}$, and the superscript s indicated sample. $\mathrm{m}$ was the slope of linear diagram between the change of absorption of DPBF at $418 \mathrm{~nm}\left(\Delta_{\mathrm{OD}}\right)$ and irradiation time $(\mathrm{t})$. $\mathrm{F}$ was absorption correction factor $\left(\mathrm{F}=1-10^{-\mathrm{OD}}\right)$. $\mathrm{P}$ was absorbed photon flux.

\section{DFT calculation}

The energy-minimized structures of BA-S-S, Ce6 and their monomolecular aggregates BA-SS@Ce6 were simulated by density functional theory (DFT) calculations with the Becke-3-Lee-YangParr (B3LYP) exchange function using the Gaussian 09 (Revision E.01) package. ${ }^{1}$ The 6-31G $(\mathrm{d}, \mathrm{p}$ ) basis sets were employed. Meanwhile, time-dependent DFT (TD-DFT) investigations were performed to explore the energy difference in their singlet $\left(\mathrm{S}_{1}\right)$ and triplet $\left(\mathrm{T}_{1}\right)$ excited states.

\section{Molecular Dynamics Simulation}

The MD simulations were performed with the COMPASS force field using the Materials Studio 2019 (MS) ${ }^{\mathrm{TM}}$ software. $^{2}$ First, the DFT-optimized structures of BA-S-S and Ce6 are chosen as the starting configurations. Then, twelve BA-S-S molecules and three Ce6 molecules are randomly distributed in the simulation water box sized $3.6 \times 3.6 \times 3.6 \mathrm{~nm}^{3}$ and the density was set to $1.0 \mathrm{~g} \cdot \mathrm{cm}^{-3}$. After initial energy minimization with 1000 steps of steepest descent minimization and successively annealing at NVE ensemble ( $298 \mathrm{~K}-500 \mathrm{~K}$ ) for $20 \mathrm{ps,} \mathrm{the} \mathrm{system} \mathrm{was} \mathrm{performed} \mathrm{for} \mathrm{a} \mathrm{total} \mathrm{simulation}$ time of $5.0 \mathrm{~ns}$ in an NVT ensemble (298 K) by Forcite model block with Berendsen thermostat used. The simulation time step was 1 fs, and the particle mesh Ewald method was used to calculate electrostatic interactions. Meanwhile, the cut-off distance for nonbonded interaction was truncated at $12.5 \AA$. 


\section{Cell culture}

Mouse breast cancer cells 4T1 were purchased from Shanghai Cell Bank, Chinese Academy of Sciences. And the cells were cultured in RMPI-1640 medium supplemented with $20 \%$ FBS containing $1 \%$ antibiotic at $37{ }^{\circ} \mathrm{C}$ under a $95 \%$ humidified atmosphere with $5 \% \mathrm{CO}_{2}$.

\section{Cellular uptake of BA-S-S/Ce6 NPs}

$4 \mathrm{~T} 1$ cells were seeded into a 6 -well plate at a density of $10^{5}$ cells/well and incubated in an incubator overnight. Then the culture medium was replaced with $2 \mathrm{~mL}$ of free Ce6 or BA-S-S/Ce6 NPs (equivalent concentration of Ce6: $4 \mu \mathrm{g} / \mathrm{mL}$ ) fresh medium, and further incubated for 5 min and 1 h. After fixing with glutaraldehyde $(0.25 \%)$ and staining with DAPI PBS solutions, the cells were imaged under fluorescent inverted microscope (FIM). And the mean fluorescence intensities were evaluated by Image $\mathbf{J}$ software.

\section{In Vitro Cytotoxicity studies}

The cytotoxicity of BA-S-S and light activatable activity of free Ce6 or BA-S-S/Ce6 NPs were measured by a standard MTT assay. Typically, 4T1 cells were seeded into a 96-well plate at a density of $1 \times 10^{4}$ per well for $24 \mathrm{~h}$. Then, the cells were treated with various concentrations of drugs. For irradiation groups, after incubation of drugs for $4 \mathrm{~h}$, the cells were irradiated for by $675 \pm 10 \mathrm{~nm}$ light $\left(150 \mathrm{~mW} / \mathrm{cm}^{2}\right)$ for $10 \mathrm{~min}$ and subsequently incubated for additional $20 \mathrm{~h}$. For un-irradiation groups, the cells were incubated with drugs until for $24 \mathrm{~h}$. Afterwards, the medium was replaced with $100 \mu \mathrm{L}$ of fresh medium containing MTT $(0.5 \mathrm{mg} / \mathrm{mL})$ and further incubated for $4 \mathrm{~h}$ at $37{ }^{\circ} \mathrm{C}$. Then discarding the medium and dissolving the formazan crystals with $150 \mu \mathrm{L}$ of DMSO. Finally, the absorbance at $492 \mathrm{~nm}$ of the plates was analyzed with a microplate reader. The cell viability was calculated according to the following formula.

$$
\text { Cell Viability }(\%)=\frac{\mathrm{A}_{492 \mathrm{sample}}}{\mathrm{A}_{492 \mathrm{control}}} \times 100 \%
$$

In addition, the combination index (CI) analysis was analyzed by Chou-Talalay theorem calculation using CalcuSyn 2.0 software. And CI is smaller than 1 indicating a synergistic therapeutic effect.

\section{Cellular ROS generation}

For intercellular ROS generation detection, 4T1 cells were seeded in 6-well plates with a density of $10^{5}$ cells per well. After $24 \mathrm{~h}$ of incubation, the medium was replaced with $2 \mathrm{~mL}$ of fresh medium containing free Ce6 or BA-S-S/Ce6 NPs (equivalent Ce6: $1.5 \mu \mathrm{g} / \mathrm{mL}$ ) and further incubated for $4 \mathrm{~h}$. Subsequently, $25 \mu \mathrm{M}$ DCFH-DA culture medium was added and incubated for additional $30 \mathrm{~min}$. After washing twice with PBS, the cells were irradiated with or without light for 6 min and incubated for another $10 \mathrm{~min}$, and then imaged by FIM (excited with Blue). The cells without any treatment were set as blank control. 


\section{Biosafety of BA-S-S/Ce6 NPs}

Normal mouse fibroblast cell line (L929) were cultured in RMPI-1640 medium supplemented with $10 \%$ FBS containing of $1 \%$ antibiotic at $37{ }^{\circ} \mathrm{C}$, and then seeded in 96 -well plates. Subsequently, the cells were incubated for $24 \mathrm{~h}$ with $100 \mu \mathrm{l}$ various concentrations of BA-S-S/Ce6 NPs (Eq. Ce6: 0.1, $0.25,1,2,4 \mu \mathrm{g} / \mathrm{mL})$. Cell viability was quantified by MTT assays.

\section{Hemolysis analysis}

Hemolysis analysis was used to evaluate the blood compatibility of BA-S-S/Ce6 NPs. Briefly, $10 \%$ (v/v) mouse blood red cells PBS solutions were first prepared. Then the mixture contains $200 \mu \mathrm{L}$ of red blood cells and $800 \mu \mathrm{L}$ of various concentrations of BA-S-S/Ce6 NPs PBS dispersion incubated for $4 \mathrm{~h}$ at room temperature. Subsequently, the sample supernatants were obtained after centrifugation at $13000 \mathrm{rpm}$ for $10 \mathrm{~min}$ and measured the Uv absorption of $577 \mathrm{~nm}$. The PBS and distilled water were added as negative and positive group, respectively. The Hemolytic percent was calculated as follows: $\left[\mathrm{A}_{\text {sample}}-\mathrm{A}_{\mathrm{PBS}}\right] /\left[\mathrm{A}_{\text {sample-}} \mathrm{A}_{\mathrm{PBS}}\right] \times 100 \%$. Where $\mathrm{A}_{\text {Sample }}, \mathrm{A}_{P B S}$, and $\mathrm{A}_{\text {water }}$ are the absorbance of each sample, PBS and distilled water, respectively.

\section{Animal models}

Female Balb-c mice (18-22 g, 6-7 weeks old) were purchased from the Second Affiliated Hospital of Harbin Medical University. All animal experiments were performed under the guidelines for Animal Care and Use of Laboratory Animals, following protocols approved by the Institutional Animal Care and Use Committee (IACUC) at the Harbin Medical University, China. 4T1 cells were collected and suspended In RMPI-1640 medium, and subcutaneously injected into the right-back of each mice.

\section{In vivo bio-distribution of BA-S-S/Ce6 NPs}

4T1 tumor-bearing Balb-c mice with approximately $75-100 \mathrm{~mm}^{3}$ of tumor volumes were randomly assigned to two groups, and intravenously injected with $200 \mu \mathrm{L}$ of BA-S-S/Ce6 NPs (equivalent Ce6: $0.35 \mathrm{mg} / \mathrm{mL}$ ) or free Ce6, respectively. Then, at a predetermined time, the mice were anesthetized with isoflurane and placed onto the warmed stage for imaging using AniView 100/600 Multi-model in vivo animal imaging system (Guangzhou Biolight Biotechnology Co., Ltd, China) with the excitation at $630 \mathrm{~nm}$. Finally, the mice were sacrificed, and the major organs (heart, liver, spleen, lung, and kidney) and tumors were collected for ex vivo imaging. To evaluate the accumulation of BA-S-S/Ce6 NPs in the tissues, the fluorescence intensity was quantified using the internal software of the instrument.

\section{In vivo antitumor evaluation of BA-S-S/Ce6 NPs}

4T1 tumor-bearing Balb-c mice (tumor volumes: $75-100 \mathrm{~mm}^{3}$ ) were randomly assigned to five 
groups ( $n=5$ for each group) and intravenously injected with $200 \mu \mathrm{L}$ of (i) $5 \%$ glucose aqueous solution, (ii) free Ce6, (iii) free Ce6 with irradiation, (iv) BA-S-S/Ce6 NPs, (v) BA-S-S/Ce6 NPs with irradiation at equivalent Ce6 of $3.5 \mathrm{mg} / \mathrm{kg}$ body. The mice were injected three times at the 0 th, 2nd and 4th day, with the first injection day designated as day 0 . For irradiation groups, the mice were anesthetized with isoflurane at $6 \mathrm{~h}$ post-injection after each administration, and then the tumor site were irradiated by $675 \pm 10 \mathrm{~nm}$ light $\left(150 \mathrm{~mW} / \mathrm{cm}^{2}\right)$ for $15 \mathrm{~min}$. The tumor volume was monitored every two days with a caliper and calculated according to the formula: volume $=($ tumor length $) \times(\text { tumor width })^{2} \times 0.5$. Mice body weight were also recorded as indicators of systemic toxicity. After 14 days of tumor monitoring, all mice were euthanized, and the tumors and major organs were collected and weighed. The tumor inhibition ratio (TIR) was calculated according to the equation:

$$
\operatorname{TIR}(\%)=\left(1-\frac{\mathrm{m}_{\text {sample }}}{\mathrm{m}_{\text {control }}}\right) \times 100 \%
$$

Where $m_{\text {sample }}$ and $m_{\text {control }}$ were the average tumor weight of each treated group and $5 \%$ glucose aqueous solution group, respectively.

Meanwhile, the organs index was calculated by the formula: organ index $=\mathrm{W}_{1} / \mathrm{W}_{2}$, where $\mathrm{W}_{1}$ and $\mathrm{W}_{2}$ represent the average weight of organ $(\mathrm{mg})$ and mice body weight before dissection $(\mathrm{g})$, respectively.

\section{Histological and TUNEL assays}

After 14 days of treatment, all mice were euthanized and major organs (heart, liver, spleen, lung, and kidney) and tumors were collected fixed with a $10 \%$ neutral buffered formalin and stained with haematoxylin and eosin (H\&E) for histological analysis. Besides, Terminal deoxynucleotidyl transferase-mediated deoxyuridine triphosphate nick end labelling (TUNEL, Roche Diagnostic, Indianapolis, IN, USA) was performed to assess the tumor apoptosis levels in each group.

\section{Blood Chemistry}

At the end of the treatment, the mice blood were collected carefully and kept at $4{ }^{\circ} \mathrm{C}$ for $2 \mathrm{~h}$. After centrifugation at $3000 \mathrm{rpm}$ for $10 \mathrm{~min}$ at $4{ }^{\circ} \mathrm{C}$, the blood serum was obtained for measuring aspartate aminotransferase (AST), alanine aminotransferase (ALT), alkaline phosphatase (ALP), creatinine (CREA), uric acid (UA), Urea (UREA), albumin (ALB), and total bilirubin (TBIL) using an Automatic Biochemical Analyzer (Hitachi 7100, Japan).

\section{Statistical analysis}

The data in this paper was expressed as a mean \pm standard deviation. Data were analyzed by $\mathrm{t}$-tests with SPSS 22.0 software. A probability values $<0.05$ was considered significant. Statistical significance: $* P<0.05, * * P<0.01, * * * P<0.001$. 
Table

Table S1. Dynamic light scattering (DLS) analysis of BA-S-S/Ce6 NPs

\begin{tabular}{cccc}
\hline $\begin{array}{c}\text { Different ratio of } \\
\text { BA-S-S to Ce6 }\end{array}$ & Diameter $(\mathrm{nm})$ & PDI & Zeta potential $(\mathrm{mV})$ \\
\hline $1: 1$ & $248.4 \pm 18.6$ & 0.382 & $-11.6 \pm 2.3$ \\
$2: 1$ & $216.5 \pm 10.9$ & 0.412 & $-14.5 \pm 0.9$ \\
$4: 1$ & $207.8 \pm 4.9$ & 0.153 & $-12.3 \pm 1.5$ \\
$6: 1$ & $231.5 \pm 7.2$ & 0.222 & $-12.0 \pm 1.3$ \\
$8: 1$ & $231.5 \pm 3.2$ & 0.391 & $-13.6 \pm 0.7$ \\
\hline
\end{tabular}

\section{Additional Figures}

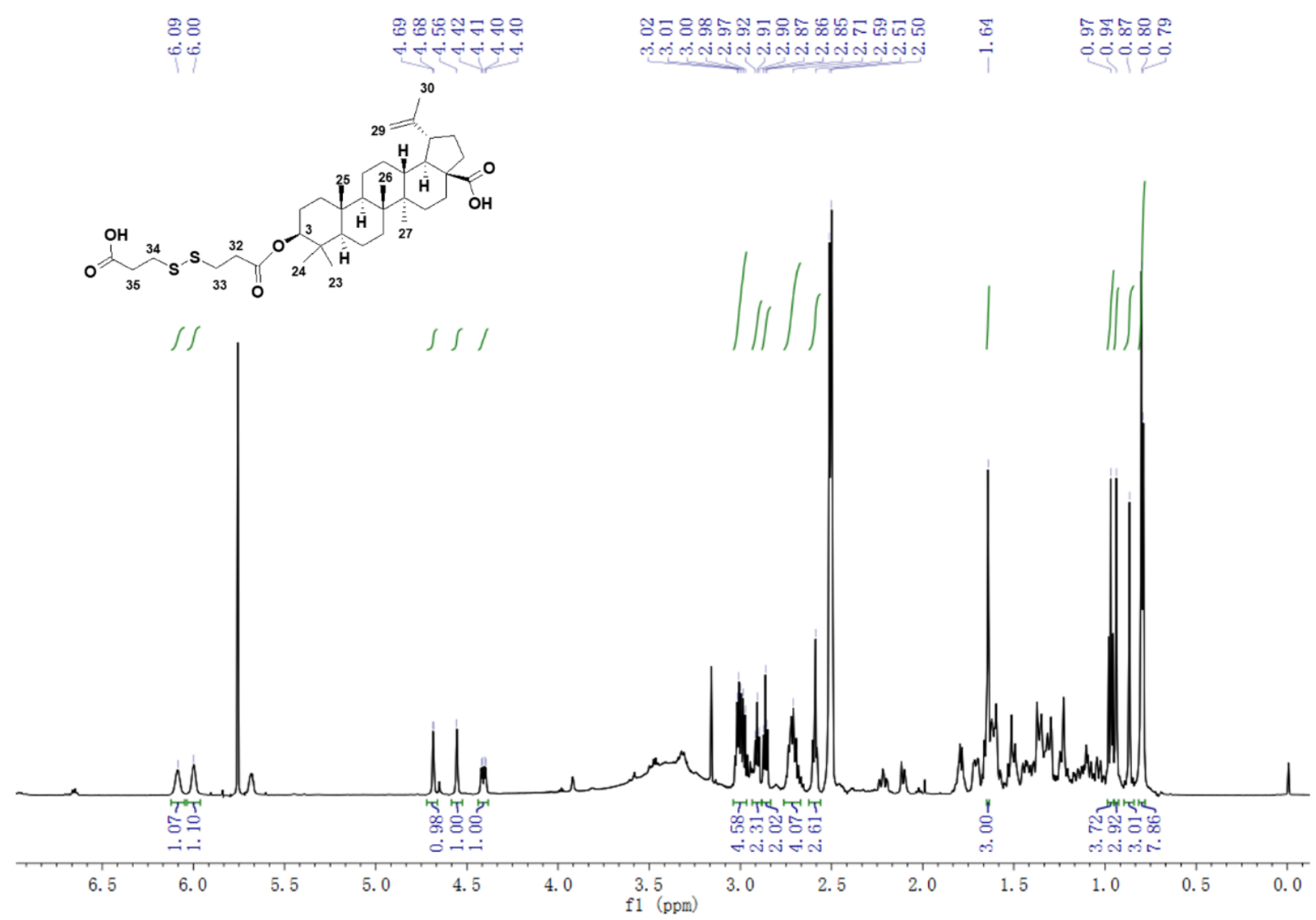

Figure S1. ${ }^{1} \mathrm{H}-\mathrm{NMR}$ spectra of 3-(3, 3'-dithiodipropionic acid) betulinic acid (BA-S-S) in DMSO-D6. 


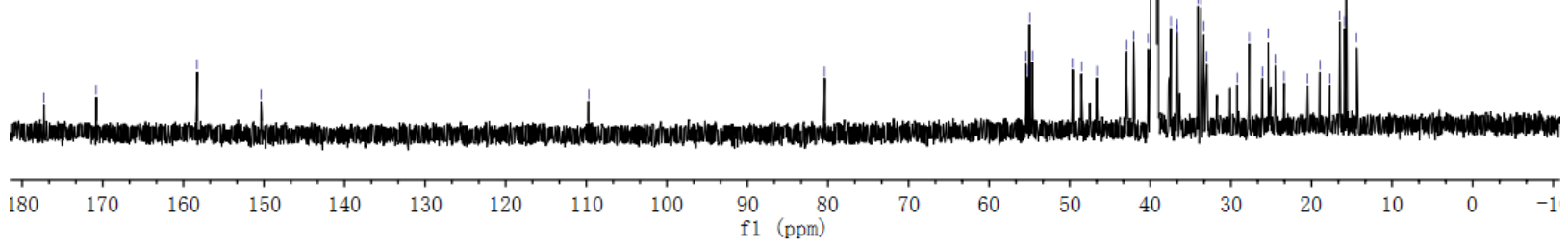

Figure S2. ${ }^{13} \mathrm{C}-\mathrm{NMR}$ spectra of BA-S-S in DMSO-D6.
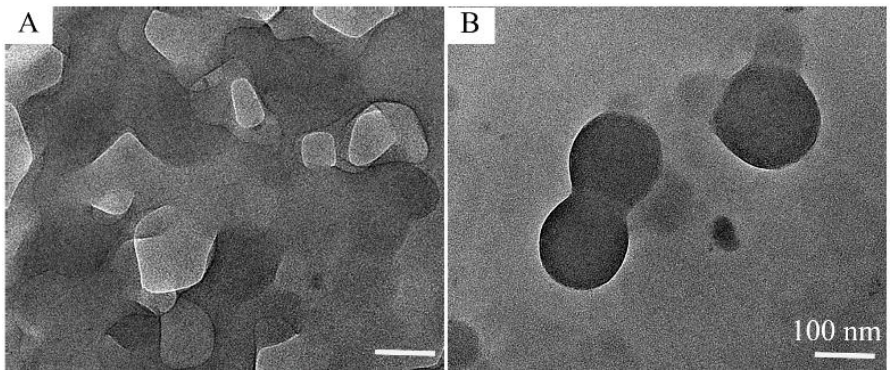

Figure S3. TEM images of BA-S-S self-assemblies (A) and BA-S-S/Ce6 NPs (B), respectively. Scale bar: $100 \mathrm{~nm}$. 


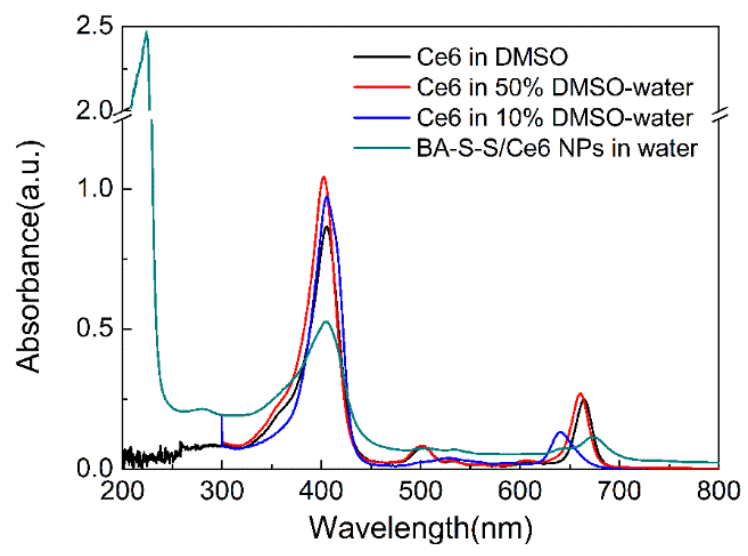

Figure S4. Uv-vis spectra of co-assembled BA-S-S/Ce6 NPs in water, monomeric Ce6 in DMSO, individual Ce6 aggregates in 50\% DMSO-water and 10\% DMSO-water (equivalent concentration of Ce6: $4.0 \mu \mathrm{g} / \mathrm{mL}$ ), respectively. As the increase of water proportion, the Qy bands exhibited significant blue-shift with reduced absorbance, while no obvious shift of Soret bands in Ce6 aggregates could be observed, suggesting the formation of H-type aggregates. ${ }^{3}$

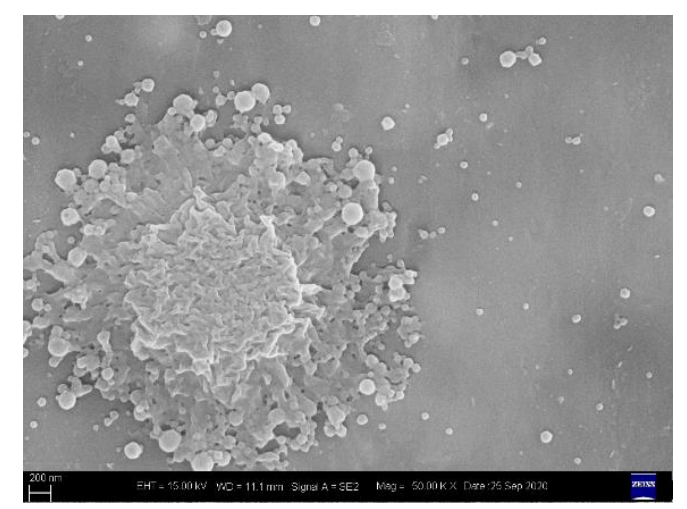

Figure S5. SEM image of BA-S-S/Ce6 NPs obtained without sonication.

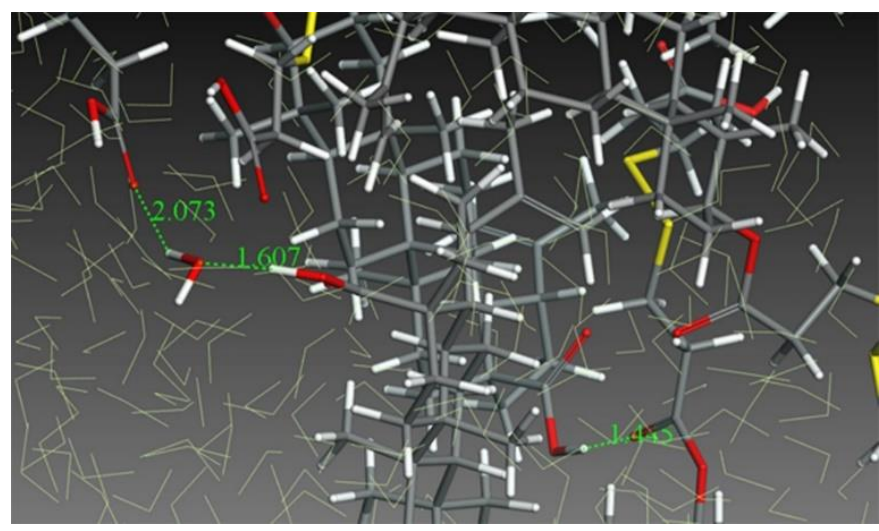

Figure S6. The water bridge through one water molecule by two hydrogen bonds exist in two BA-S$\mathrm{S}$ molecules. 


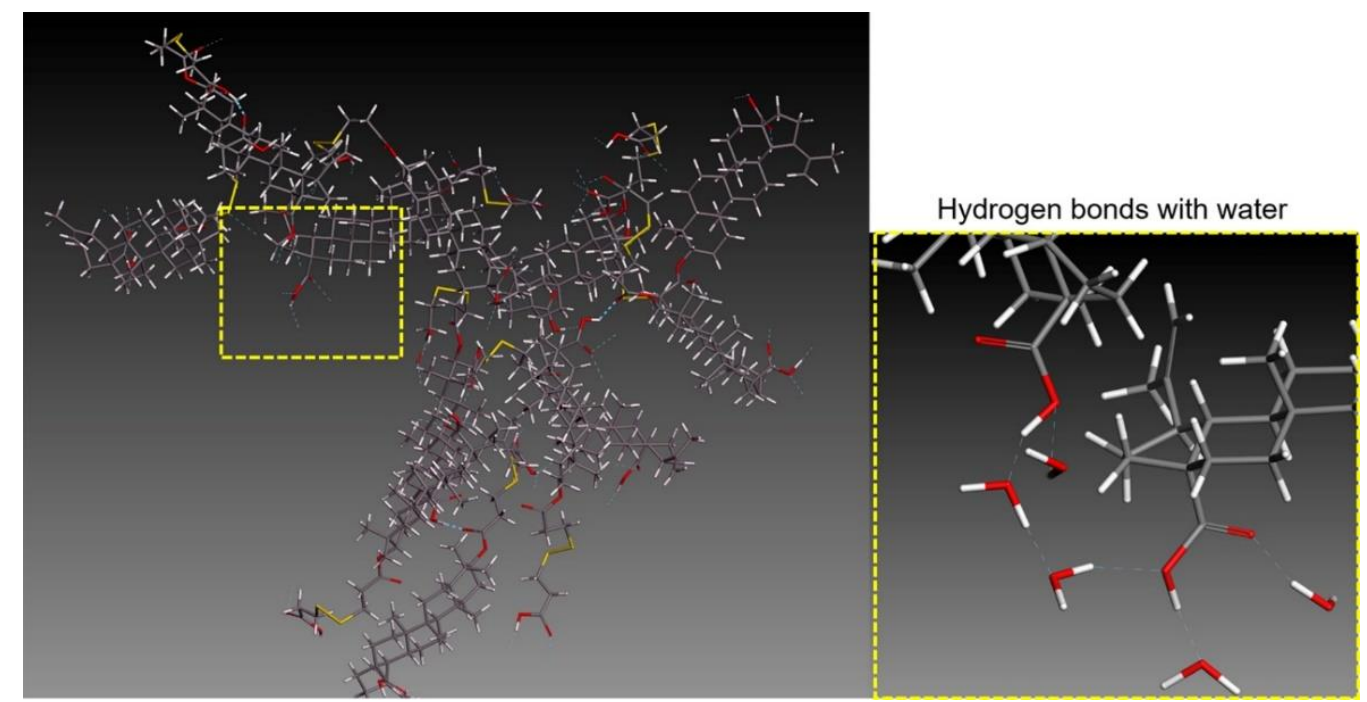

Figure S7. The hydrogen bond information of BA-S-S self-assemblies after MD simulation for $5 \mathrm{ns,}$ and water molecules are omitted. There are a large mumble of hydrogen bonds between BA-S-S and water molecules existing in BA-S-S self-assemblies.
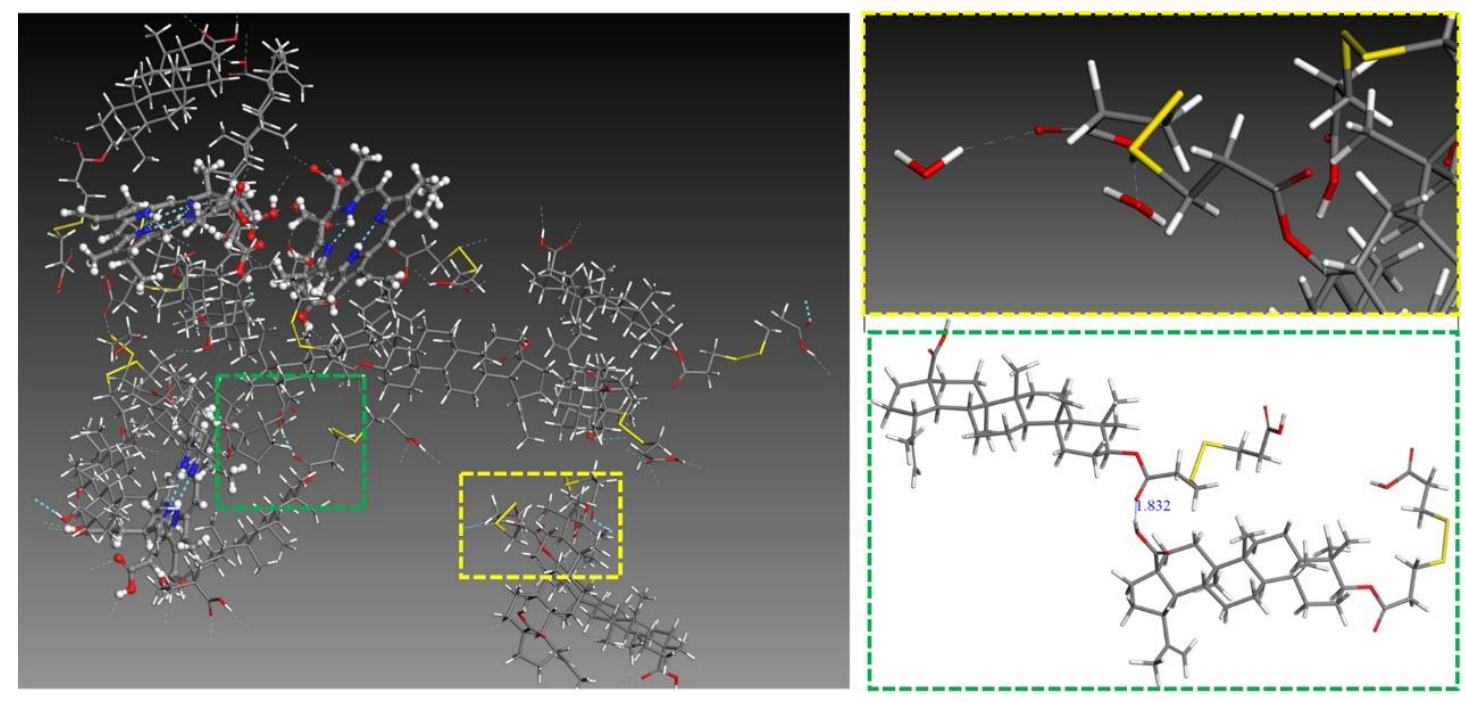

Figure S8. The hydrogen bond information of BA-S-S/Ce6 co-assemblies after MD simulation for 5 ns, and water molecules are omitted. Only one pair of intermolecular hydrogen bond among BA-S-S molecules, numerous hydrogen bonds between BA-S-S with water also existed in co-assemblies. 


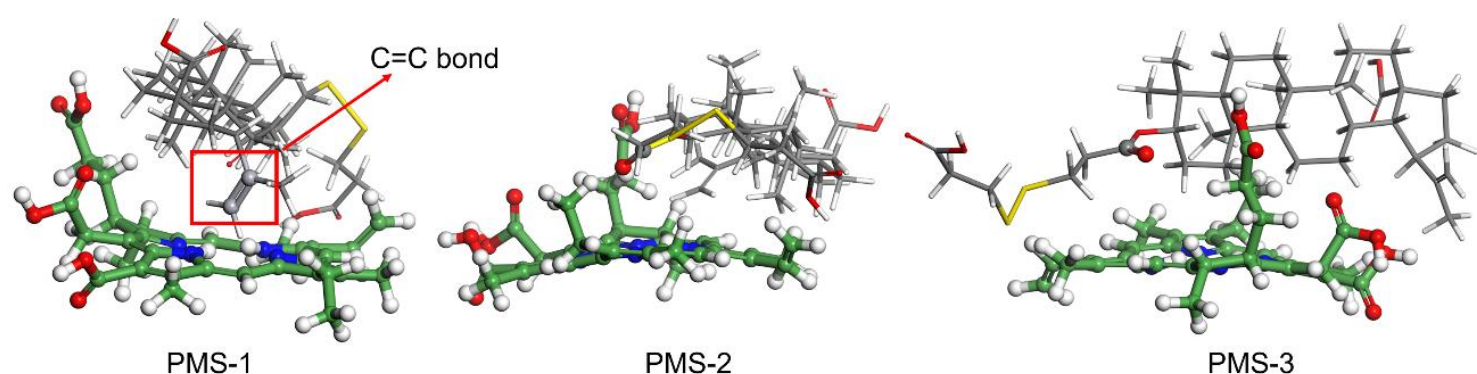

PMS-1

PMS-2

PMS-3

Figure S9. The side views of possible molecular interactions between Ce6 with BA-S-S (PMS-1, PMS-2, PMS-3) after MD simulation.
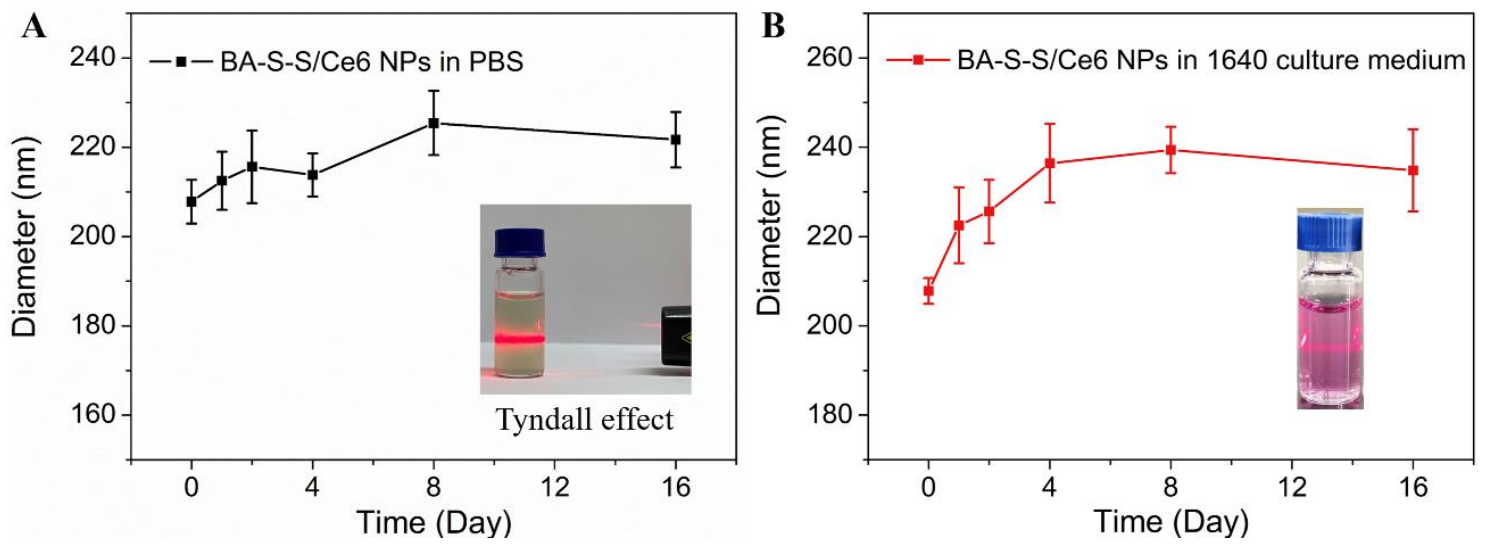

Figure S10. Size change of BA-S-S/Ce6 NPs during incubation in (A) PBS and (B) 1640 culture medium for 16 days. And BA-S-S/Ce6 NPs showed better water solubility and a remarkable Tyndall effect, indicating a colloidal nature. Notably, BA-S-S/Ce6 NPs have an increase in size by around 30 $\mathrm{nm}$ after incubation in 1640 culture medium, which may be attributable to the protein adsorption in the medium around the nanoparticles. 


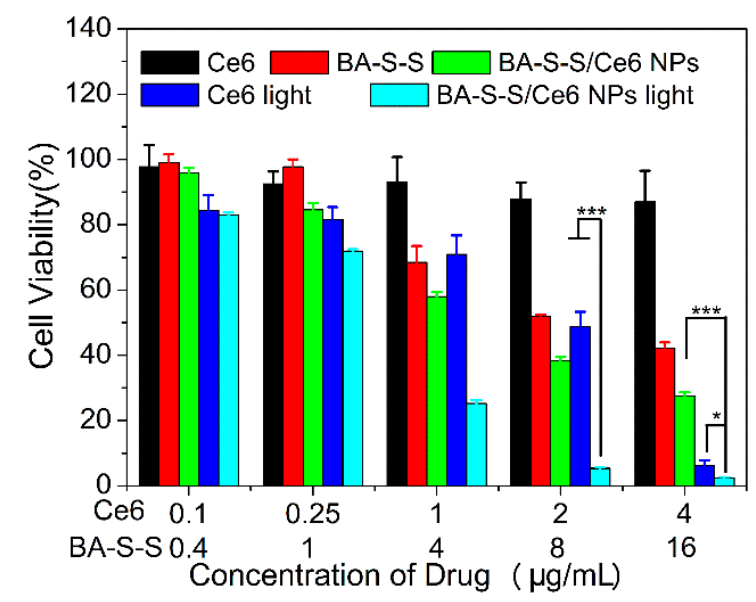

Figure S11.Cell cytotoxicity of Ce6, BA-S-S, BA-S-S/Ce6 NPs in dark or under irradiation with $675 \pm 10 \mathrm{~nm}$ light $\left(150 \mathrm{~mW} / \mathrm{cm}^{2}\right)$ against human MCF-7 cells after incubation for $24 \mathrm{~h}$.

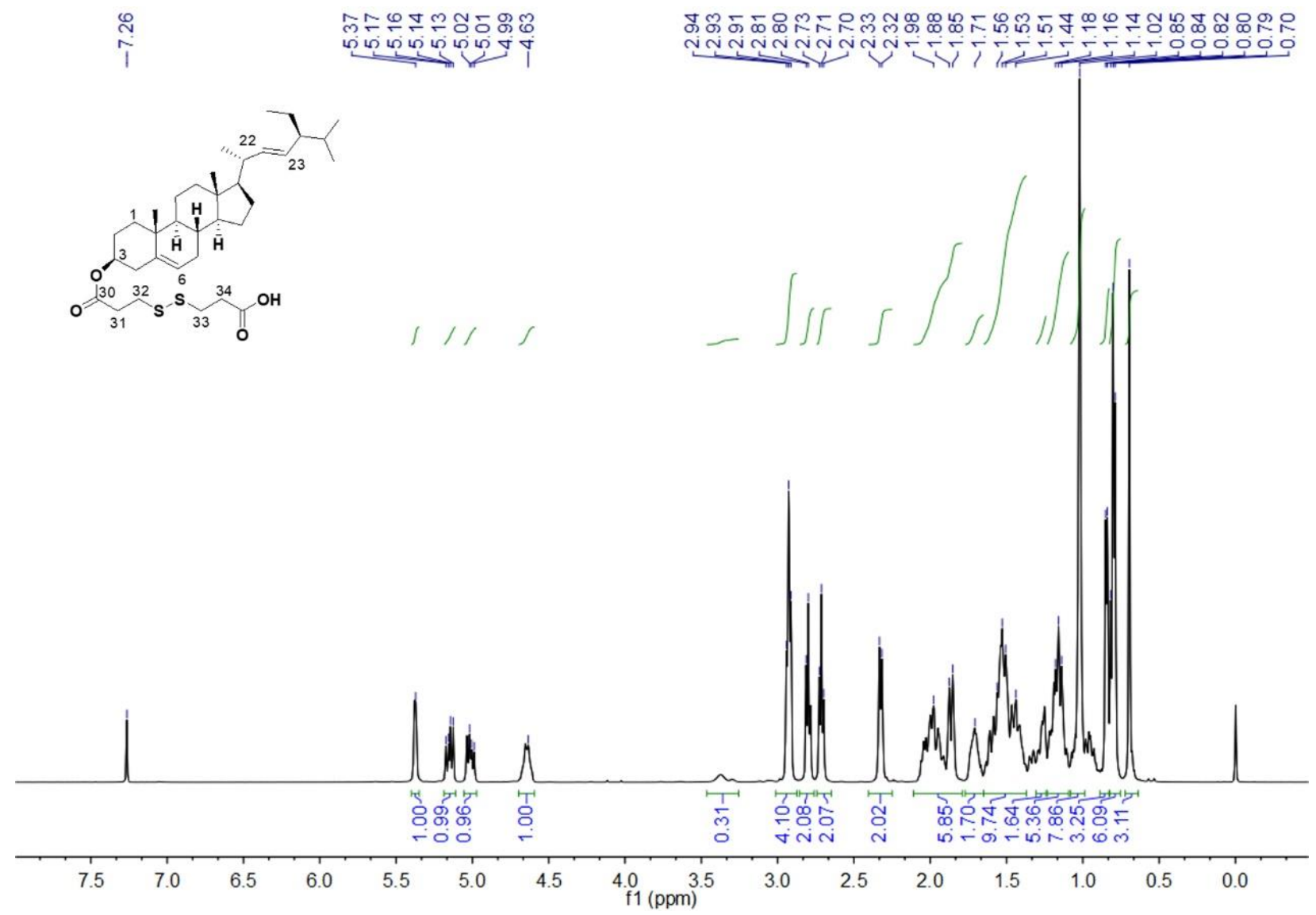

Figure S12. ${ }^{1} \mathrm{H}-\mathrm{NMR}$ spectra of 3-(3, 3'-dithiodipropionic acid) stigmasterol (ST-S-S) in $\mathrm{CDCl}_{3}$. 


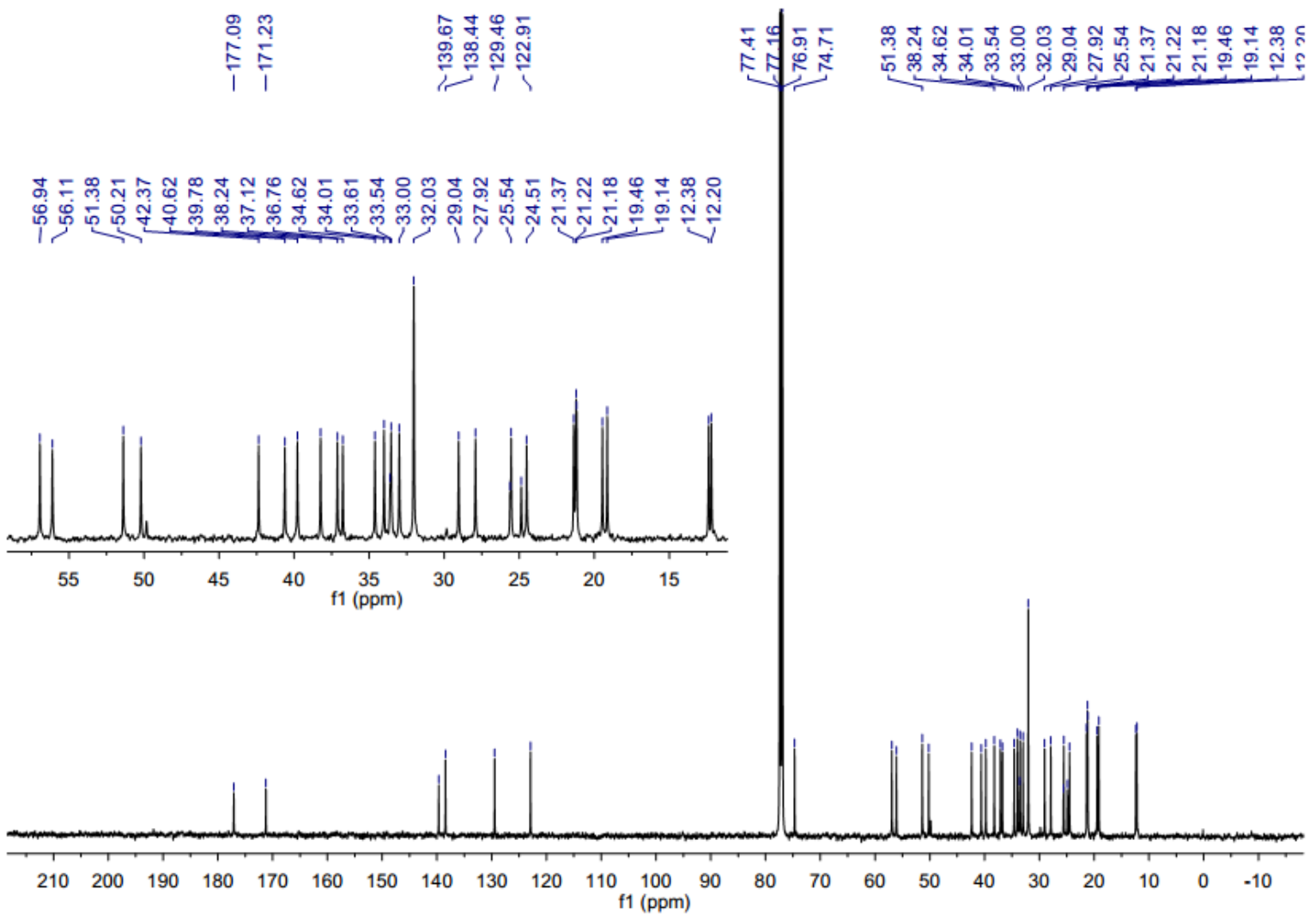

Figure S13. ${ }^{13} \mathrm{C}$-NMR spectra of 3-(3, 3'-dithiodipropionic acid) stigmasterol (ST-S-S) in $\mathrm{CDCl}_{3}$.

\section{Reference}

1. Gaussian 09, Revision E.01, M. J. Frisch, G. W. Trucks, H. B. Schlegel, G. E. Scuseria, M. A. Robb, J. R. Cheeseman, G. Scalmani, V. Barone, B. Mennucci, G. A. Petersson, H. Nakatsuji, M. Caricato, X. Li, H. P. Hratchian, A. F. Izmaylov, J. Bloino, G. Zheng, J. L. Sonnenberg, M. Hada, M. Ehara, K. Toyota, R. Fukuda, J. Hasegawa, M. Ishida, T. Nakajima, Y. Honda, O. Kitao, H. Nakai, T. Vreven, J. A. Montgomery, Jr., J. E. Peralta, F. Ogliaro, M. Bearpark, J. J. Heyd, E. Brothers, K. N. Kudin, V. N. Staroverov, T. Keith, R. Kobayashi, J. Normand, K. Raghavachari, A. Rendell, J. C. Burant, S. S. Iyengar, J. Tomasi, M. Cossi, N. Rega, J. M. Millam, M. Klene, J. E. Knox, J. B. Cross, V. Bakken, C. Adamo, J. Jaramillo, R. Gomperts, R. E. Stratmann, O. Yazyev, A. J. Austin, R. Cammi, C. Pomelli, J. W. Ochterski, R. L. Martin, K. Morokuma, V. G. Zakrzewski, G. A. Voth, P. Salvador, J. J. Dannenberg, S. Dapprich, A. D. Daniels, O. Farkas, J. B. Foresman, J. V. Ortiz, J. Cioslowski, and D. J. Fox, Gaussian, Inc., Wallingford CT, 2013.

2. Liu, K.; Kang, Y.; Ma, G.; Möhwald, H.; Yan, X. Molecular and Mesoscale Mechanism for Hierarchical Self-Assembly of Dipeptide and Porphyrin Light-Harvesting System. Phys. Chem. Chem. Phys. 2016, 18, 16738-16747.

3. Liang, R.; Tian, R.; Ma, L.; Zhang, L.; Hu, Y.; Wang, J.; Wei, M.; Yan, D.; Evans, D. G.; Duan, X. A Supermolecular Photosensitizer with Excellent Anticancer Performance in Photodynamic Therapy. Adv. Funct. Mater. 2014, 24, 3144-3151. 